\title{
Evidence for density dependent population regulation in southern elephant seals in the southern Indian Ocean
}

\author{
P.A. Pistorius*, F.E. Taylor, M.N. Bester, G.J.G. Hofmeyr \& S.P. Kirkman \\ Mammal Research Institute, Department of Zoology and Entomology, University of Pretoria, Pretoria, 0002 South Africa \\ Received 13 July 2007. Accepted 6 December 2007
}

\begin{abstract}
The means by which populations are regulated form a central theme in conservation biology, and much debate has revolved around density dependence as a mechanism driving population change. Marion Island $\left(46^{\circ} 54^{\prime} \mathrm{S}, 37^{\circ} 45^{\prime} \mathrm{E}\right)$ is host to a relatively small breeding population of southern elephant seals, which like its counterparts in the southern Indian and southern Pacific Oceans, have declined precipitously over the past few decades. An intensive markrecapture study, which commenced in 1983, has yielded a long time-series of resight data on this population. We used the program MARK to estimate adult female survival in this population from resight data collected over the period 1986-1999. Including concurrent population counts as covariates significantly improved our mark-recapture models and suggests density dependent population regulation to be operational in the population. Although predation may have been involved, it is far more likely that density dependent regulation has been based on a limited food supply. A significant increase in adult female survival was evident which is likely to have given rise to recent changes in population growth.
\end{abstract}

Key words: density dependence, southern elephant seals, Marion Island, population regulation.

\section{INTRODUCTION}

Southern elephant seal (Mirounga leonina) numbers have declined at most breeding populations in the Southern Indian and Pacific Oceans over the past several decades (Hindell \& Burton 1987; Guinet et al. 1992; Bester \& Wilkinson 1994; Pistorius et al. 1999a), and hypotheses accounting for this have recently been reviewed by McMahon et al. (2005). Similar to other sites (Guinet et al. 1999; Slip \& Burton 1999), the Marion Island (465'S, $37^{\circ} 45^{\prime} \mathrm{E}$; located in the southern Indian Ocean, approximately $2180 \mathrm{~km}$ southeast of Cape Town, South Africa; Fig. 1) population has now stabilized (Pistorius et al. 2004). An intensive demographic study initiated on the small population at Marion Island in 1983 has yielded consistent mark-recapture data. Several research papers have stemmed from this long-term data series detailing temporal patterns in survival (e.g. Pistorius et al. 1999b; Pistorius \& Bester 2002; McMahon et al. 2003; Pistorius et al. 2004) and fecundity (Pistorius et al. 2001).

Some of the more noteworthy conclusions emanating from this demographic research were that fecundity increased and age of sexual maturity decreased over the duration of the study, arguably as a compensatory response in the declining population (Pistorius et al. 2002). Furthermore, adult female survival increased with the stabilization of the population (Pistorius et al. 2004), whereas juvenile survival was independent of the change in population growth rate (see Fig. 1 for first-year survival estimates; Pistorius \& Bester 2002). These changes in adult female population parameters were argued to have been mediated through a relative increase in per capita food availability, implicating a density dependent response. Density dependence, defined as a causal relationship in which some feedback mechanism links the density of a population to one or more of its demographic rates, thus determining its future density (Sale \& Tolimieri 2000), was, however, not explicitly tested for in these studies.

The aim of this study is to explicitly test for density dependence in adult female survival in southern elephant seals at Marion Island by applying modern statistical modelling techniques to a long-term mark-recapture dataset with concurrent population counts.

\section{METHODS}

\section{Data collection}

Between 1983 and 1995, 3270 (average: 252 annually, range: 198-343) recently weaned female southern elephant seal pups were tagged in each 


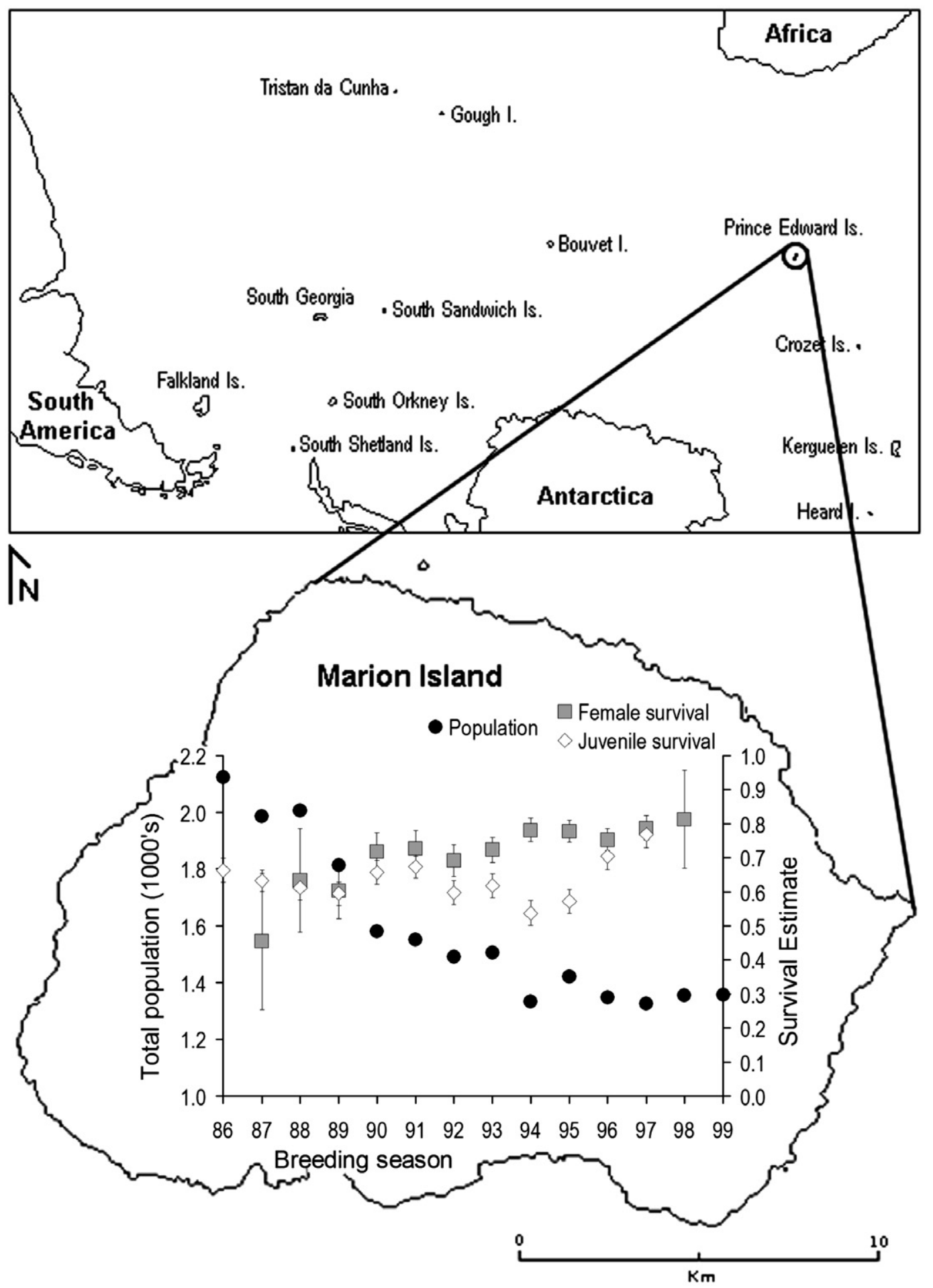

Fig. 1. Adult female and first-year survival in relation to changes in the size of the population of southern elephant seals at Marion Island. Survival estimates were taken from the time-dependent model without any constraints on survival and population estimates were taken from Pistorius et al. (2004). 
Table 1. The number of marked southern elephant seal females recorded breeding for the first time on Marion Island (primiparous) and sightings of all marked females between 1986 and 1999.

\begin{tabular}{|c|c|c|c|c|c|c|c|c|c|c|c|c|c|c|}
\hline Year & 1986 & 1987 & 1988 & 1989 & 1990 & 1991 & 1992 & 1993 & 1994 & 1995 & 1996 & 1997 & 1998 & 1999 \\
\hline Primiparous & 11 & 19 & 37 & 68 & 88 & 79 & 101 & 75 & 59 & 78 & 68 & 66 & 7 & 105 \\
\hline Total & 11 & 22 & 45 & 92 & 145 & 153 & 193 & 204 & 215 & 248 & 234 & 254 & 34 & 216 \\
\hline
\end{tabular}

of their hind flippers on Marion Island, using uniquely numbered, colour-coded Dal 008 Jumbo$\operatorname{tags}^{\circledR}$ (Dalton Supplies Ltd., Henley-on-Thames, United Kingdom) (see Pistorius et al. 2000 for details). The data collection for this study commenced in 1986 when the first females from the 1983 cohort reached reproductive status. Every seven days during the southern elephant seal breeding season on Marion Island (early August to mid November: Wilkinson 1992; Kirkman et al. 2003), all the breeding colony beaches were routinely searched for tagged females for the duration of this study. The tag number and colour combination of each tagged female observed during these surveys were recorded.

\section{Data analyses}

An encounter-history matrix (incorporating the resight data of all individuals in a binary format) was constructed from the resight data of parous females treating the first sighting of a female during the breeding season as the initial release (Table 1). Pistorius et al. (2004) found no significant age-dependent variation in survival of parous southern elephant seal females from our study population. Age-parameters were consequently not considered in our present analysis. Multiple sightings during any given breeding season were treated as a single sighting. Resight data up to the year 1999 were used, which yielded 13 resight occasions for females breeding in 1986. The software program MARK (G. White, Colorado State University; White \& Burnham 1999), which is an application for the analysis of encounter-history matrices of marked individuals, was used to obtain likelihood estimates of annual survival and resight probabilities of adult females. The software program provides parameter estimates under the essential Cormack-Jolly-Seber (CJS) model, but also under several models that appear as special cases of this model (Lebreton et al. 1992).

The two fundamental parameters in these models are: $\phi=$ the survival probability for all animals between the $i$ th and $(i+1)$ th encounter occasion $(i=1, \ldots, k-1)$, and $P=$ the resighting probability for all animals in the $i$ th encounter occasion $(i=$ $1, \ldots, k)$.

The survival probability incorporates both death and permanent emigration of individuals and can therefore be referred to as apparent survival. Southern elephant seals in general, but particularly breeding females, show a strong site fidelity to their natal grounds (Hofmeyr 2000) and we consequently expect permanent emigration from our study site to be minimal.

We tested the fit of our global model to the data with the program RELEASE goodness-of-fit procedure (Burnham et al. 1987) implemented in the program MARK to check whether the assumptions pertaining to the CJS model were met (see Lebreton et al. 1992).

Our global model included time-dependence (i.e. separate estimates for each year) in both survival and capture probability. We considered a set of models, including models with and without patterns of temporal variation in resight and survival parameters. Models with survival of firstyear breeders alone, as well as of survival of all females, constrained to be a logistic-linear function of population size (directly prior to the year for which survival was estimated; in other words the population estimate in 1986 was used as a covariate of survival between October 1986 and 1987 and so forth) as well as a linear function of time were included in the model set.

Population estimates were taken from Pistorius et al. (2004). We also considered a model with survival maintained as constant over the period that the population was stable (1994 onwards; Pistorius et al. 2004) and over the period that the population was declining (prior to 1994). Akaike's Information Criterion (AIC) was used to select between these models with various constraints (Lebreton et al. 1993; Anderson et al. 1994). The model with the lowest AIC provides the best basis for inference by including only those effects that are supported by the data. The models were ranked relative to deviations from the best model $(\triangle \mathrm{AIC})$, and models with $\triangle \mathrm{AIC}$ of less than two 
Table 2. Akaike information criteria (AICc), delta AIC ( $\triangle \mathrm{AICc}$ ), Akaike weights, number of parameters (np) and the deviance for the candidate survival $(\phi)$ and resight $(p)$ models.

\begin{tabular}{|c|c|c|c|c|c|}
\hline Model & $\mathrm{AICc}$ & $\triangle \mathrm{AICc}$ & AICc weights & $\mathrm{np}$ & DEV \\
\hline \multirow{10}{*}{$\begin{array}{l}\phi_{\mathrm{T} * \log \text { density, }} \mathrm{p}_{\mathrm{T}} \\
\phi_{\mathrm{T} \text { *linear, }} \mathrm{p}_{\mathrm{T}} \\
\phi_{94,} \mathrm{p}_{\mathrm{T}} \\
\phi_{\mathrm{C}}, \mathrm{p}_{\mathrm{T}} \\
\phi_{\mathrm{R} 1 * \text { linearR2T, }} \mathrm{p}_{\mathrm{T}} \\
\phi_{\mathrm{T}}, \mathrm{p}_{\mathrm{T}} \\
\phi_{\mathrm{R} 1 \mathrm{~T} * \text { log densityR2T, }}, \mathrm{p}_{\mathrm{T}} \\
\phi_{\mathrm{R} 1 \mathrm{C} \& \mathrm{R} 2-\mathrm{T},} \mathrm{p}_{\mathrm{T}} \\
\phi_{\mathrm{R} 1 \& \mathrm{R} 2-\mathrm{T},} \mathrm{p}_{\mathrm{T}} \\
\phi_{\mathrm{T},} \mathrm{p}_{\mathrm{C}}\end{array}$} & 3493.251 & 0.000 & 0.517 & 15 & 495.687 \\
\hline & 3493.405 & 0.154 & 0.479 & 15 & 495.842 \\
\hline & 3499.036 & 5.790 & 0.028 & 15 & 501.472 \\
\hline & 3502.747 & 9.496 & 0.004 & 14 & 507.216 \\
\hline & 3503.007 & 9.765 & 0.004 & 25 & 484.993 \\
\hline & 3509.806 & 16.556 & 0.000 & 25 & 491.791 \\
\hline & 3511.937 & 18.686 & 0.000 & 25 & 493.923 \\
\hline & 3516.661 & 23.411 & 0.000 & 26 & 496.588 \\
\hline & 3516.812 & 23.561 & 0.000 & 37 & 473.958 \\
\hline & 3721.692 & 228.42 & 0.000 & 14 & 726.141 \\
\hline
\end{tabular}

Key: $\phi_{\mathrm{T}}$ : time-dependent survival rate; $\phi_{\mathrm{C}}$ : constant survival rate; $\mathrm{p}_{\mathrm{T}}$ : time-dependent capture probability; $\mathrm{p}_{\mathrm{C}}$ : constant capture probability; $\mathrm{R} 1$ : first-time breeders; R2: experienced breeders

are generally considered to have good support (Anderson \& Burnham 1999).

We corrected our survival estimates to compensate for tag loss in this study despite the very low loss rates reported for the population (Pistorius et al. 2000).

\section{RESULTS}

The CJS model adequately fitted the adult female resight data from our study population $\left(\chi^{2}=\right.$ 35.072 , d.f. $=34, P=0.417$ ).

A model with time-dependent resight probability had much better support than a model in which this parameter was constrained to be constant over time (Table 2). The probability of resighting an individual during the breeding season of 1998 was exceptionally low $(0.118$ : $95 \%$ CI 0.071-0.189) as a result of poor resight effort. For the remaining years it varied between $0.526(95 \%$ CI 0.245-0.791) in 1987 and 0.871 (95\% CI 0.7880.925) in 1997.

A model with population size as a covariate of survival had much better support than the full time-dependent or constant survival model (Table 2) implicating density dependence in adult female survival. A similar pattern was evident when only considering primiparous females (Table 2, AIC 3511.94 vs 3516.81). There was similar support for the density dependent model and the next best model which had survival constrained to be a linear function of time (AICc weights 0.517 and 0.479 , respectively; Table 2). According to the second model, survival increased linearly over the study period from 0.625 (95\% CI $0.544-0.699)$ in 1986 to $0.819(0.771-0.859)$ in 1998 with a slope of 0.083 (95\% CI 0.034-0.132). A linear increase in survival of primiparous females was also evident (Table 2, slope $0.134,95 \%$ CI 0.058-0.210). According to the two-stage model, survival was $5.45 \%$ higher during the period that the population was stable (0.775: $95 \%$ CI $0.741-0.805)$ compared to while it was in decline $(0.775$ : $95 \%$ CI0.741-0.805).

\section{DISCUSSION}

Our results suggest a density dependent pattern in survival of females at Marion Island, which increased over the study period with the stabilization of the population. From 1986 onwards, an increasing number of older or more experienced females would have been recruited into our data set. The trend in survival for all females could therefore arguably have resulted from a larger proportion of young females early on in the study. These young females may potentially have had relatively low survival resulting from inexperience or due to reduced site fidelity which would have lowered apparent survival in a CJS model context (Lebreton et al. 1993). Survival during the year following primiparity, however, also demonstrated a density dependent pattern and increased linearly over time similar to survival of all females combined. This suggests that the above is an unlikely source of bias in our study. Adult female southern elephant seals at Marion Island furthermore exhibit similar levels of site fidelity independent of experience (Pistorius et al. 2004).

It should be noted that our annual estimates of population size at Marion Island were based on single counts and we could not include variance of these estimates in our models. Population estimates at Marion Island are based on adult female counts on the peak haul-out date during the 
breeding season (see Pistorius et al. 1999a). Bias associated with these counts is likely to be minimal due to the ease of counting adult females in this small population.

With the virtual absence of land-based mortality in adult females at Marion Island, the density feedback on adult female survival observed in this study would have come into play during their pelagic phase. Both density dependent changes in predatory pressure and food availability could have given rise to the pattern observed in this study.

Killer whales (Orcinus orca) are the primary predators of southern elephant seals but it has been argued that they have a relatively small impact on the southern elephant seal population at Marion Island (Pistorius et al. 2002). Most killer whales sighted off Marion Island are predominantly in the near-shore area (Keith et al. 2001; Pistorius et al. 2002) where newly weaned southern elephant seal pups remain during play and local postweaning dispersion (Lenglart \& Bester 1982; Wilkinson \& Bester 1990). This age class is therefore likely to form the preferential prey and a high predation rate by killer whales on juveniles have been reported at Îles Crozet (Guinet et al. 1992). The steep rise in adult female survival with decreasing density, coupled with a relatively stable juvenile survival (Pistorius \& Bester 2002) militate against predation by killer whales having given rise to the pattern observed in this study.

Although there is no direct evidence in support of this, changes in per capita food availability provides a more parsimonious explanation for density dependence in southern elephant seal survival. Food resources are probably a limiting resource in our study population as has been previously speculated (Pistorius et al. 1999b; McMahon et al. 2005). Adult female southern elephant seals haul out for between three to four weeks during both the moulting and breeding seasons. During these periods, the seals fast and are nutritionally stressed when they return to sea (Boyd et al. 1993; Carlini et al. 2005). We would consequently expect that food limitation is the most severe in the vicinity of Marion Island soon after the females have returned to sea.

Several studies have demonstrated that density dependence in mammals primarily affects the adult segment of the population (e.g. FestaBianchet et al. 2003; Owen-Smith et al. 2005; OwenSmith 2006). Similarly, at Marion Island, juvenile survival of southern elephant seals showed no ap- parent trend in the declining population (Pistorius \& Bester 2002) while adult female survival demonstrated a significant density dependent increase (Pistorius et al. 2004; present study).

The increase in adult female survival observed here coincided with the stabilization of our study population around 1994 after a long-term decline (Pistorius et al. 2004). Population counts at Marion Island subsequent to 1999 demonstrate that the elephant seal population remained stable since then (unpubl. data; MRI). In the absence of a notable increase in juvenile survival over the study period (Pistorius \& Bester 2002) we expect that the increase in adult female survival was fundamentally related to the stabilization and possible reversal of a long-term population decline.

\section{ACKNOWLEDGEMENTS}

The Department of Environmental Affairs and Tourism provided financial and logistical support for research at Marion Island on the advice of the South African Scientific Committee for Antarctic Research (SASCAR) and SACAR, respectively. The first author benefited from a National Research Foundation Grant-holder linked post-doctoral bursary within the project 'Conservation of Seabirds, Shorebirds and Seals' that funds a consortium of researchers led by L. Underhill of the Avian Demography Unit, Department of Statistical Sciences, University of Cape Town.

\section{REFERENCES}

ANDERSON, D.R. \& BURNHAM, K.P. 1999. General strategies for the analysis of ringing data. Bird Study 46: $261-270$.

ANDERSON, D.R., BURNHAM, K.P. \& WHITE, G.C. 1994. AIC model selection in overdispersed capturerecapture data. Ecology 75: 1780-1793.

BESTER, M.N. \& WILKINSON, I.S. 1994. Population ecology of southern elephant seals at Marion Island. In: Elephant Seals: Population Ecology, Behavior, and Physiology, (eds) R.J. Le Boeuf \& R.M. Laws, pp. 85-97. University of California Press, Berkeley.

BOYD, I.L., ARNBOM, T.A. \& FEDAK, M.A. 1993. Water flux, body composition and metabolic rate during molt in female southern elephant seals (Mirounga leonina). Physiological Zoology 66: 43-60.

BURNHAM, K.P., ANDERSON, D.R., WHITE, G.C., BROWNIE, C. \& POLLOCK, K.H. 1987. Design and analysis methods for fish survival experiments based on release-recapture. American Fisheries Society Monographs No. 5.

CARLINI, A.R., DANERI, G.A., MÁRQUEZ, M.E.I., BORNEMANN, H., PANARELLO, H., CASAUX, R., RAMDOHR, S. \& PLÖTZ, J. 2005. Food consumption estimates of southern elephant seal females during their post-breeding aquatic phase at King George Island. Polar Biology 28: 769-775. 
FESTA-BIANCHET, M., GAILLARD, J-M. \& COTE, S.D. 2003. Variable age structure and apparent density dependence in survival of adult ungulates. Journal of Animal Ecology 72: 640-649.

GUINET, C., JOUVENTIN, P. \& WEIMERSKIRCH, H. 1992. Population changes, movements of southern elephant seals in Crozet and Kerguelen Archipelagos in the last decades. Polar Biology 12: 349-356.

GUINET, C., JOUVENTIN, P. \& WEIMERSKIRCH, H. 1999. Recent population change of the southern elephant seal at Iles Crozet and Îles Kerguelen: the end of the decrease? Antarctic Science 11: 193-197.

HINDELL, M.A. \& BURTON, H.R. 1987. Past and present status of the southern elephant seal (Mirounga leonina) at Macquarie Island. Journal of Zoology, London 213: 365-380.

HOFMEYR, G.J.G. 2000. Dispersal and dispersion of southern elephant seals at Marion Island. M.Sc. thesis, University of Pretoria, Pretoria, South Africa.

KEITH, M., BESTER, M.N., BARLETT, P.A. \& BAKER, D. 2001. Killer whales (Orcinus orca) at Marion Island, Southern Ocean. African Zoology 36: 163-175.

KIRKMAN, S.P., BESTER, M.N., PISTORIUS, P.A., HOFMEYR, G.J.G., JONKER, F.C., OWEN, R. \& STRYDOM, N. 2003. Variation in the timing of moult in southern elephant seals at Marion Island. South African Journal of Wildlife Research 33: 79-84.

LEBRETON, J. BURNHAM, K.P., CLOBERT, J. \& ANDERSON, D.R. 1992. Modelling survival and testing biological hypotheses using marked animals: a unified approach with case studies. Ecological Monographs 62: 67-118.

LEBRETON, J., PRADEL, R. \& CLOBERT, J. 1993. The statistical analysis of survival in animal populations. Trends in Ecology and Evolution 8: 91-95.

LENGLART, P.Y. \& BESTER, M.N. 1982. Post-weaning dispersion of southern elephant seals Mirounga leonina underyearlings at Kerguelen. Revue d' Ecologie 36: 175-186.

McMAHON, C.R., BESTER, M.N., BURTON, H.R., HINDELL, M.A. \& BRADSHAW, C.J.A. 2005. Population status, trends and a re-examination of the hypotheses explaining the recent declines of the southern elephant seal Mirounga leonina. Mammal Reviews 35: 82-100.

McMAHON, C.R., BURTON, H.R. \& BESTER, M.N. 2003. A demographic comparison of two southern elephant seal populations. Journal of Animal Ecology 72: 61-74.

OWEN-SMITH, N. 2006. Demographic determination of the shape of density dependence for three African ungulate populations. Ecological Monographs 76: 93-109.

OWEN-SMITH, N., MASON, D.R. \& OGUTU, J.O. 2005. Correlates of survival rates for ten African ungulate populations: density, rainfall and predation. Journal of Animal Ecology 74: 774-788.

PISTORIUS, P.A. \& BESTER, M.N. 2002. Juvenile survival and population regulation in southern elephant seals at Marion Island. African Zoology 37: 35-41.

PISTORIUS, P.A., BESTER, M.N. \& KIRKMAN, S.P. 1999a. Dynamic age-distributions in a declining population of southern elephant seals. Antarctic Science 11: $445-450$.

PISTORIUS, P.A., BESTER, M.N. \& KIRKMAN, S.P. 1999b. Survivorship of a declining population of southern elephant seals, Mirounga leonina, in relation to age, sex, and cohort. Oecologia 121: 201-211.

PISTORIUS, P.A., BESTER, M.N., KIRKMAN, S.P. \& BOVENG, P.L. 2000. Evaluation of age- and sexdependent rates of tag loss in southern elephant seals. Journal of Wildlife Management 64: 373-380.

PISTORIUS, P.A., BESTER, M.N., LEWIS, M.N., TAYLOR, F.E., CAMPAGNA, C. \& KIRKMAN, S.P. 2004. Adult female survival, population trend, and the implications of early primiparity in a capital breeder, the southern elephant seal (Mirounga leonina). Journal of Zoology, London 263: 107-119.

PISTORIUS, P.A., TAYLOR, F.E., LOUW, C., HANISE, B., BESTER, M.N., DE WET, C., DU PLOOY, A., GREEN, N., KLASEN, S., PODILE, S. \& SCHOEMAN, J. 2002. Distribution, movement, and estimated population size of killer whales (Orcinus orca) at Marion Island, December 2000. South African Journal of Wildlife Research 32: 86-92.

SALE, P.F. \& TOLIMIERI, N. 2000. Density dependence at some time and place. Oecologia 124: 166-171.

SLIP, D.J. \& BURTON, H.R. 1999. Population status and seasonal haulout patterns of the southern elephant seal (Mirounga leonina) at Heard Island. Antarctic Science 11: 38-47.

WHITE, G.C. \& BURNHAM, K.P. 1999. Program MARK: survival estimation from populations of marked animals. Bird Study 46 Suppl.: 120-138.

WILKINSON, I.S. 1992. Factors affecting reproductive success of southern elephant seals, Mirounga leonina, at Marion Island. Ph.D. thesis, University of Pretoria, Pretoria, South Africa.

WILKINSON, I.S. \& BESTER, M.N. 1990. Duration of post-weaning fast and local dispersion in the southern elephant seal, Mirounga leonina, at Marion Island. Journal of Zoology, London 222: 591-600.

Responsible Editor: C.L. Griffiths 